\title{
NUMERICAL STUDY ON TEMPORAL DOMAIN DISCRETIZING FOR HYDROGEOLOGICAL MODELING PRACTICES
}

\author{
MOHAMED AMINE BOUKHEMACHA - PhD, Technical University of Civil Engineering of Bucharest, \\ Groundwater Engineering Research Center, e-mail: boukhemacha-amine@hotmail.com
}

CONSTANTIN RADU GOGU - PhD, Technical University of Civil Engineering of Bucharest, Groundwater Engineering Research Center, e-mail: radu.gogu@utcb.ro

IOAN BICA - Professor, PhD, Technical University of Civil Engineering of Bucharest, Groundwater Engineering Research Center, e-mail: bica@utcb.ro

\begin{abstract}
One of the key operations in the construction of hydrogeological models is the transformation of continuous physical systems into discrete models while conserving the aimed model performance level and optimizing the available resources. Such operation is called discretization, and it has to be applied to both spatial and temporal domains in hydrogeology. The present paper deals with the temporal domain discretization. A literature review is given first, and then a parametric study (using 1D flow modeling) is conducted to assess the effects induced by boundary conditions (specified head or specified recharge rate), data temporal resolution and model simulation time step on hydrogeological flow model performances. It was found that the effect induced by the dynamic comportment of a recharge rate boundary condition type is more important than that due to a specified head. For the recharge rate, the time step must be smaller or equal to the data resolution when using Modflow. As for a specified head boundary condition type, it was recommended to take a time step satisfying $\Delta t \propto 1 /(K \times \Delta h)$.
\end{abstract}

Keywords: hydrogeological modeling; temporal domain discretizing; data temporal resolution; simulation time step

\section{Introduction}

The dynamic character of groundwater is relatively slow and the response to changing boundary conditions is also slow compared to the hydrologic or surface water. In a surface-water modeling, time steps of one to several minutes are generally used. In a transient groundwater flow model time steps are often one to several days. The time factor of the hydrogeological modeling is related to:

- the hydrological processes taken in consideration (such as precipitation, evapotranspiration which in its turn depends on the other processes like temperature and relative air humidity);

- human activity (seepage/leakage into/from sewer systems, losses from water supply networks, groundwater abstraction, etc.).

An appropriate hydrogeological temporal domain discretizing has to insure the simplicity of the data requirement and a reduction of the computational cost while conserving the correct comportment of the studied system. Furthermore, many hydrological researches reported that the modeling parameters can change with the time resolution [1].

The present study is conducted in the context of the temporal hydrological domain discretizing. The authors aim at studying the effects of the temporal domain discretizing on the results of hydrogeological mathematical modeling. These effects are assessed for the most used boundary conditions (BC) types in groundwater flow modeling: i) specified head $\mathrm{BC}$ and ii) specified recharge rate $\mathrm{BC}$. The study will be conducted in terms of two time discretizing parameters: a) 
input data temporal resolution -DTR- (representing input data measurement frequency) and simulation time step-STS- (representing the numerical model integration time step).

\section{Literature Review}

Different temporal domain discretizing schemes can be found in the literature. These vary from one studied phenomena to another as they can even differ for the same phenomena depending on the used methodology and the aimed precision.

The urban water and contaminant balance analysis tool - Urban Volume and Quality (UVQ) [2], for example, uses a daily computational time step, even though some of the considered processes (such as rainfall-runoff or a toilet flash) can last from a few seconds to minutes and can take place multiple times within a day. The authors stated that a time step of 1-30 min can be required in order to represent the peak flow in the water supply which will increase the computational time 24-3600 times. Furthermore, [3] reported that the temporal variations of groundwater recharge rates (calculated using UL_FLOW model from UVQ infiltrations) were similar when using daily or monthly time steps, except the time resolution. However, yearly time steps provide only an average of the overall variation.

[4] used Richards' equation to estimate the infiltration form precipitation with an initial time step of about 1 minute during and following rainfall event followed by a 1 hour maximum model time step once the overland flow routing is completed. The authors also reported that model stability and accuracy can be increased by internally limiting the time step based on a maximum change in water content.

The groundwater recharge from precipitation model elaborated by [5] can use hourly, daily or monthly time step. By comparing the recharge rates obtained using their model with those obtained using a four-stage tank model, the authors found a similarity in the monthly recharges, while the daily and hourly ones were different.

[6] used a 1 week time step and 1 month stress period within which the specific groundwater recharge and surface water levels are constant for their large-scale groundwater model in Modflow;

For the interception, monthly (for temperature variations) or seasonal (growing and dormancy seasons) parameters variation was considered due to vegetation phenology;

For temperature, evaporation (from intercepted water, snow melt water, soil water from the first store), plant transpiration and precipitation, a daily time step was used.

[7] developed a large scale high resolution groundwater flow model using a daily time step over a simulation period of 13 years. The important CPU time needed for the calculation (estimated to be more than 20 years using a contemporary PC) was significantly reduced using grid computing (to several months using $200 \mathrm{PC}$ in parallel processing).

The temporal domain discretization is also dependent on the different methods used to quantify model inputs. For example the quantification of the infiltration using the empirical model of [8] which is considered to be more accurate for times smaller than $t_{\max }=\left(\alpha / K_{S}\right)^{1 / \beta}$, where $\alpha, \beta$ are empirical constants and $K_{s}$ is the saturated hydraulic conductivity. Such a condition leads to the use of a time step smaller than $t_{\max }$.

One can also find hydrologically founded recommendations of time step limitations that have been defined empirically. One example is that time steps should not exceed $1 / 3$ to $1 / 5$ of the time to peak of a discharge event (see [9]). The author also proposed a relationship between the time step ( $\Delta t$ taken in hours) and the catchment area $\left(A\right.$ taken in $\left.\mathrm{km}^{2}\right)$ :

$$
\Delta t=0.2 \times A^{0.54}
$$




\section{Data and Method}

\subsection{Specified Head}

Let us consider the study of input data (specified head in this part of the study) temporal resolution and the simulation time step effects on a groundwater flow model results. To do so, a 1D horizontal transient flow model in a homogenous confined aquifer is considered. In order to isolate the time effect from the considered parameter, the following boundary conditions (see Figure 1) were chosen to be applied:

- Transient specified head boundary condition in one extremity;

- Constant specified head boundary condition (of $75 \mathrm{~m}$ ) in the other extremity.

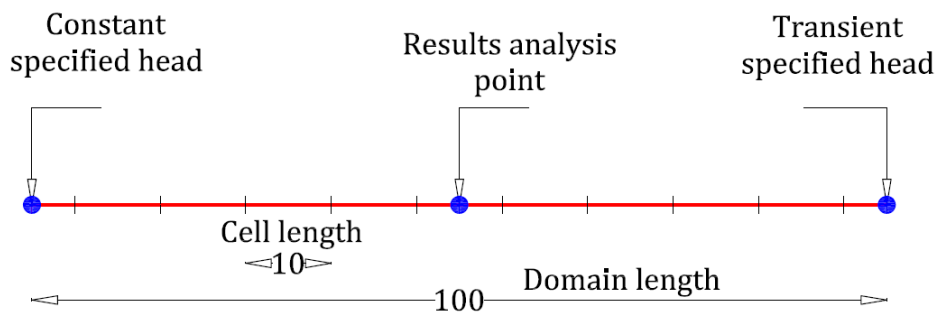

Fig. 1 - Schematization of the 1D horizontal transient flow model in a confined aquifer to study the specified head BC effect

For a full coverage of the time effect that can be met when using transient specified head $\mathrm{BC}$, the following parameters were varied using the values shown in Table 1: aquifer transmissivity, data temporal resolution (DTR) and simulation time step (STS). The transmissivity variation will represent the combined effects of the transmissivity and the distance between the transient specified head and the response point (domain midpoint).

Table 1

Parameters values for the study of the time effect from a specific head

\begin{tabular}{|l|l|l|l|l|}
\hline Parameter & \multicolumn{4}{|l|}{ Values } \\
\hline Transmissivity $\left[\mathrm{m}^{2} /\right.$ day $]$ & 1 & 10 & 100 & 1000 \\
\hline Data temporal resolution & day & week & month & quarter \\
\hline Simulation time step & day & week & month & quarter \\
\hline
\end{tabular}

The used transient specified head data for the different scenarios (different temporal resolutions) are presented in Figure 2. The data with resolutions higher than daily are obtained by averaging the daily values. The daily data represent the daily fluctuation of the water level in a lake in Bucharest.

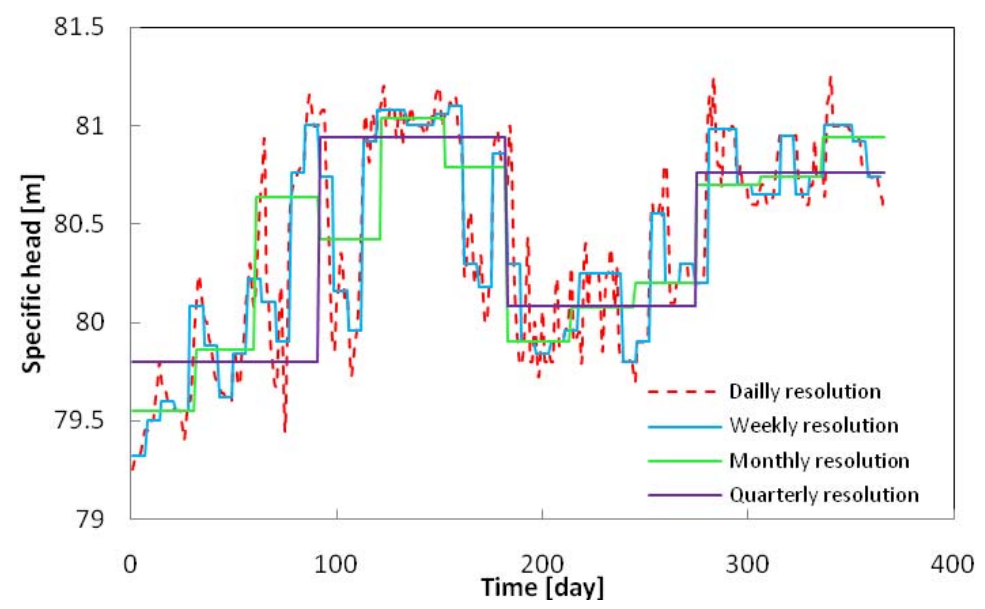

Fig. 2 - Transient specified head data at different time resolutions 
This study will be conducted by comparing the obtained variation of the hydraulic head in the midpoint of the studied domain using all possible combination of the different parameters values given in Table 1. The head estimation is done using finite difference method (simulations conducted using Modflow 2000 [10]). Result comparison will be done using the following statistical parameters:

Nash-Sutcliffe efficiency (NSE): This dimensionless parameter is a normalized statistic that determines the relative magnitude of the residual variance ("noise") compared to the measured data variance ("information") [11]. NSE indicates how well the plot of observed versus simulated data fits the 1:1 line. NSE is computed as shown in equation (2).

$$
N S E=1-\left[\frac{\sum_{i=1}^{n}\left(Y_{i}^{o b s}-Y_{i}^{s i m}\right)^{2}}{\sum_{i=1}^{n}\left(Y_{i}^{o b s}-Y^{\text {mean }}\right)^{2}}\right]
$$

Where, $Y_{i}^{o b s}$ is the $i^{\text {th }}$ observation, $Y_{i}^{\text {sim }}$ is the $i^{\text {th }}$ simulated value, $Y^{\text {mean }}$ is the mean of observed data, and $n$ is the number of observations.

NSE takes values in the interval $[1,-\infty[$ with:

- $\quad N S E=1$ : being the optimal value;

- $\quad 0 \leq N S E \leq 1$ : indicates acceptable levels of performance;

- $N S E<0$ : indicates that the mean observed value is a better predictor than the simulated value, which reflects unacceptable performance.

- Percent bias (PBIAS): This parameter measures the average tendency of the simulated data to be larger or smaller than their observed counterparts [12]. PBIAS is calculated with:

$$
\text { PBIAS }=100\left[\frac{\sum_{i=1}^{n}\left(Y_{i}^{\text {obs }}-Y_{i}^{\text {sim }}\right)}{\sum_{i=1}^{n}\left(Y_{i}^{o b s}\right)}\right]
$$

The optimal value of PBIAS is 0.0 , with low-magnitude values indicating accurate model simulation. Positive values indicate model underestimation bias, and negative values indicate model overestimation bias.

- RMSE-observations standard deviation ratio (RSR): RMSE is one of the commonly used error index statistics. Although it is commonly accepted that the lower the RMSE the better the model performance, only [13] have published a guideline to qualify what is considered a low RMSE based on the observations standard deviation. Based on the recommendation by [13], a model evaluation statistic, named the $R M S E$-observations standard deviation ratio $(R S R)$, was developed. RSR standardizes RMSE using the observation standard deviation. $R S R$ is calculated with:

$$
R S R=\frac{R M S E}{S T D E V_{i b s}}=\sqrt{\frac{\sum_{i=1}^{n}\left(Y_{i}^{o b s}-Y_{i}^{\text {sim }}\right)^{2}}{\sum_{i=1}^{n}\left(Y_{i}^{o b s}-Y^{\text {mean }}\right)^{2}}}
$$


$R S R$ varies from the optimal value of 0.0 , which indicates perfect model simulation, to a large positive value. Lower $R S R$ values indicate better model simulation performance.

The result discussion (or more exactly model performance assessment) using these parameters will be done using the values given in Table 2 recommended by [14].

Table 2

Recommended values for NSE, RSR and PBIAS from [14]

\begin{tabular}{|l|l|l|l|}
\hline Performance rating & \multicolumn{1}{|c|}{$\boldsymbol{N S \boldsymbol { E }}$} & \multicolumn{1}{c|}{$\boldsymbol{R S R}$} & \multicolumn{1}{c|}{$\boldsymbol{P B I A S}[\%]$} \\
\hline Very good & $0.75 \leq N S E \leq 1.00$ & $0.00 \leq R S R \leq 0.50$ & $P B I A S \leq \pm 10$ \\
\hline Good & $0.65 \leq N S E \leq 0.75$ & $0.50 \leq R S R \leq 0.60$ & $\pm 10 \leq P B I A S \leq \pm 15$ \\
\hline Satisfactory & $0.50 \leq N S E \leq 0.65$ & $0.60 \leq R S R \leq 0.70$ & $\pm 15 \leq P B I A S \leq \pm 25$ \\
\hline Unsatisfactory & $N S E \leq 0.50$ & $R S R>0.70$ & $P B I A S \geq \pm 25$ \\
\hline
\end{tabular}

\subsection{Specified Recharge Rate}

Let us consider the study of input data (e.g. specified recharge rate from precipitation), data temporal resolution and the simulation time step effect on a hydrogeological model results. And to do so, a 1D horizontal transient flow model in a homogenous confined aquifer is considered. In order to isolate the time effect from the considered parameter, the following boundary conditions were chosen to be applied (see Figure 3):

- Constant specified head boundary conditions (of 11 and $12 \mathrm{~m}$ ) in the domain extremities;

- Transient recharge rate boundary condition applied to the domain.

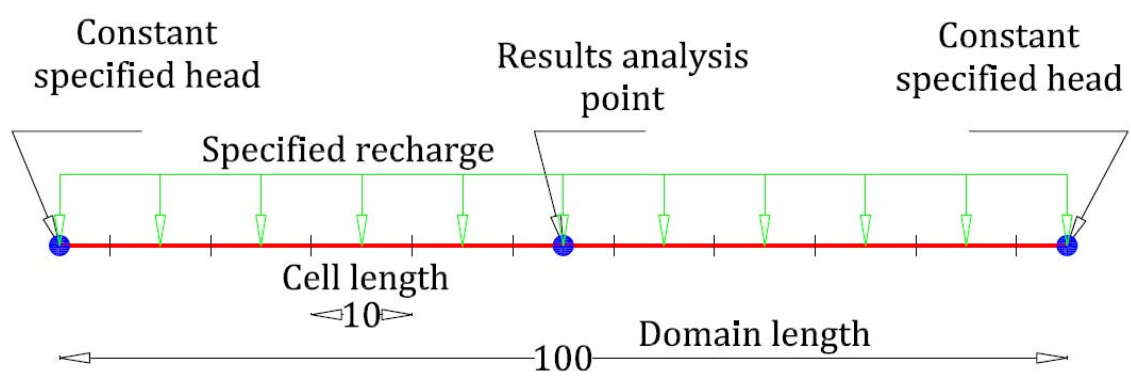

Fig. 3 - Schematization of the 1D horizontal transient flow model in a confined aquifer, the specified recharge rate $\mathrm{BC}$ effect

To assess the time effect that can be met when using a transient recharge rate $\mathrm{BC}$, the following parameters were varied using the values shown in the Table 1: data temporal resolution and simulation time step. The transmissivity was taken $T=10 \mathrm{~m} /$ day and the storativity $S=10^{-3}$. The effect of the considered parameter will be assessed from the calculated hydraulic head in the domain midpoint.

The used transient specified recharge rate data for the different scenarios (different temporal resolutions) are presented in Figure 4. The data with resolutions higher than the daily ones are obtained using averaging the daily values. The daily data represent daily estimations of the groundwater recharge from daily precipitation measured during 2010 in Buzau-Romania (Administratia Nationala de Meterologie). This recharge is assumed to be equal to $30 \%$ of the precipitation.

This study will be conducted in the same way as in the previous study. The results comparison will be done using the same statistical parameters previously presented (NSE, RSR, PBIAS). 


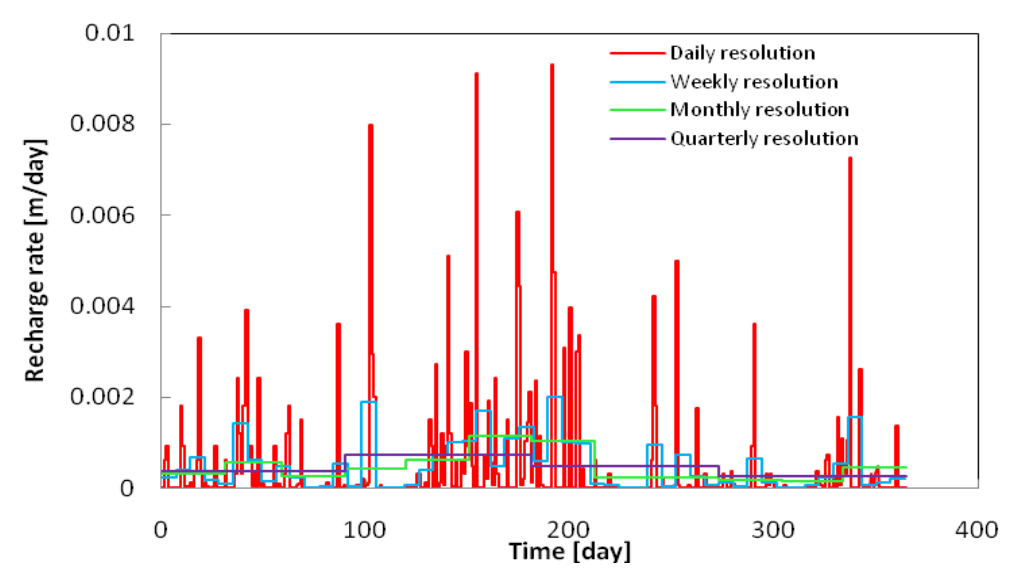

Fig. 4 - Transient specific recharge rate data at different time resolutions

\section{Results and Discussion}

\subsection{Specified Head}

The obtained variations of the hydraulic head at the midpoint of the studied domain for all possible combinations of the parameter values given in Table 1 are presented in Figure 5.
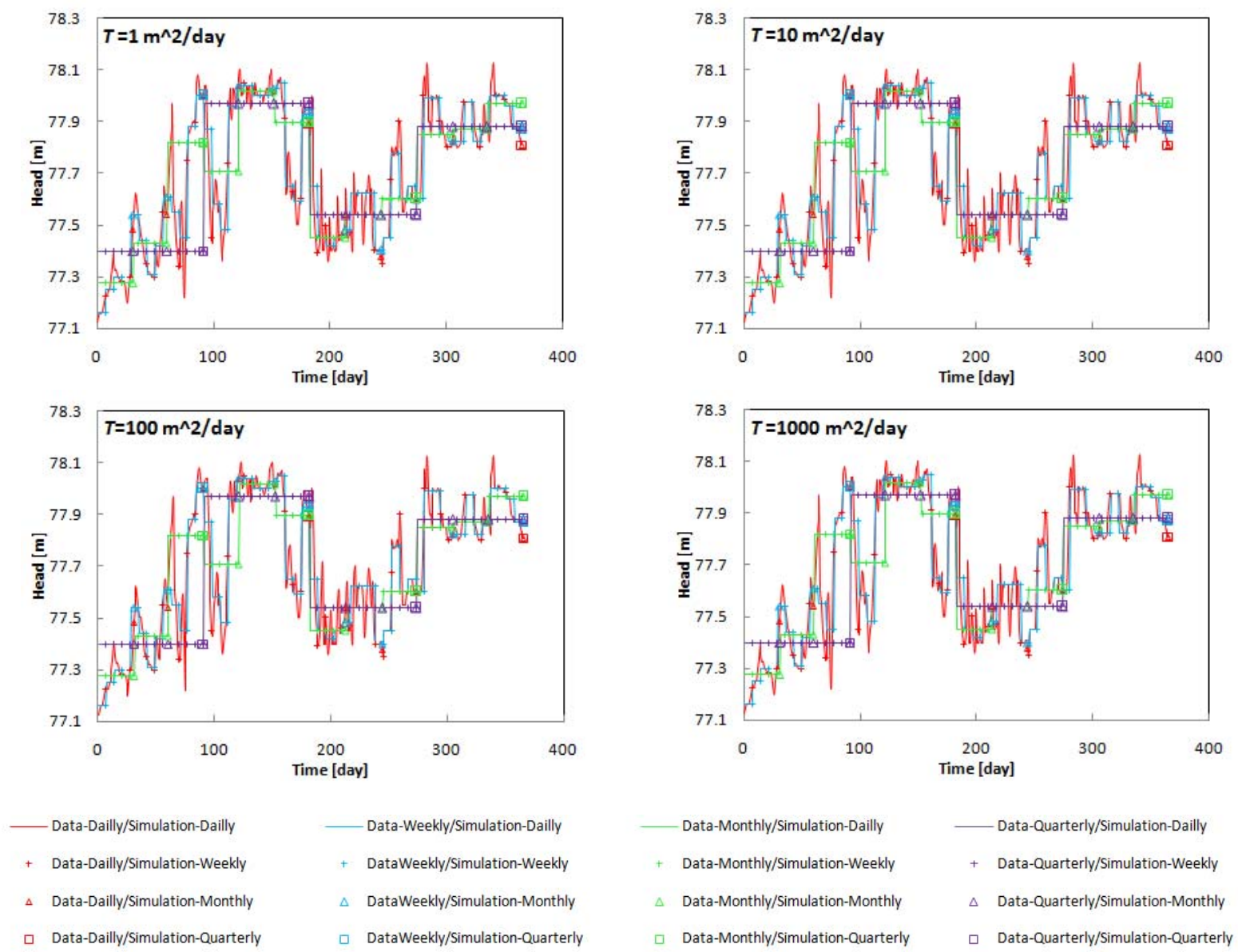

Fig. 5 - Variation of the hydraulic head in the midpoint of the studied domain (time effect from a specified head experiment)

It can be easily observed that the effect of the variation of the transmissivity is insignificant. Consequently, the discussion of the obtained results will be conducted in terms of the remaining parameters (data temporal resolution and simulation time step). 


\subsubsection{Data Temporal Resolution Variation Effect}

In order to assess the effect of the data resolution variation on the considered parameter (specified head), we will be calculating NSE, PBIAS and RSR. These calculations are conducted by comparing the calculated hydraulic head in the domain midpoint using weekly, monthly and quarterly data resolution to that calculated using a daily data resolution (that will be considered as the observed value when using equations (2-4)).

Figure 6 shows the obtained values of NSE to assess the effect of the data temporal resolution (DTR) from a specified head BC. It was found that the use of a weekly DTR gives very good performance, and the use of monthly DTR provides a good to a satisfactory performance for time steps less than quarterly ones and unsatisfactory performance for quarterly time step, while the use of quarterly DTR gives unsatisfactory performance. Similar results were obtained from the $R S R$ parameter except to the slight intrusion in the good performance zone for a daily DTR combined with a weekly simulation time step STM (see Figure 7Error! Reference source not found.). And finally the variation of the PBIAS indicates a decreasing performance when DTR decreases; this performance is qualified as very good with general tendency of overestimation when using daily DTR and underestimation for quarterly DTR (see Figure 8).

The general decrease of the performance with the decrease of DTR was expected since it is a normal response to the induced simplicity of the dynamic character of the specified head BC.

As a conclusion it is recommended to use weekly DTR when daily DTR is not applicable (for lack of data or in order to reduce computation time). The use of monthly DTR provides a good to satisfactory performance (and is to be avoided when using quarterly simulation time steps) and finally the use of quarterly DTR leads to unsatisfactory performance.

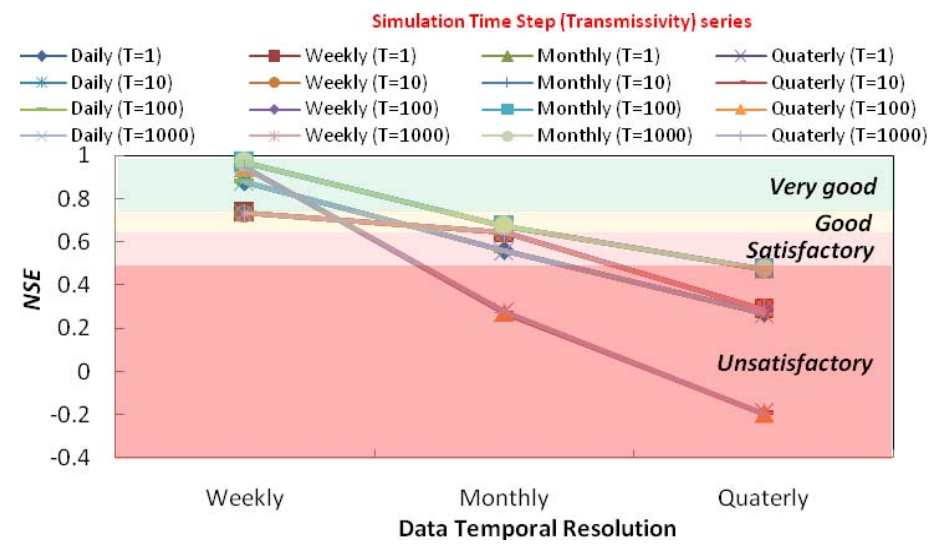

Fig. 6 - Variation of the NSE values for the different scenarios considered to illustrate the effect of the data temporal resolution from a specified head $\mathrm{BC}$

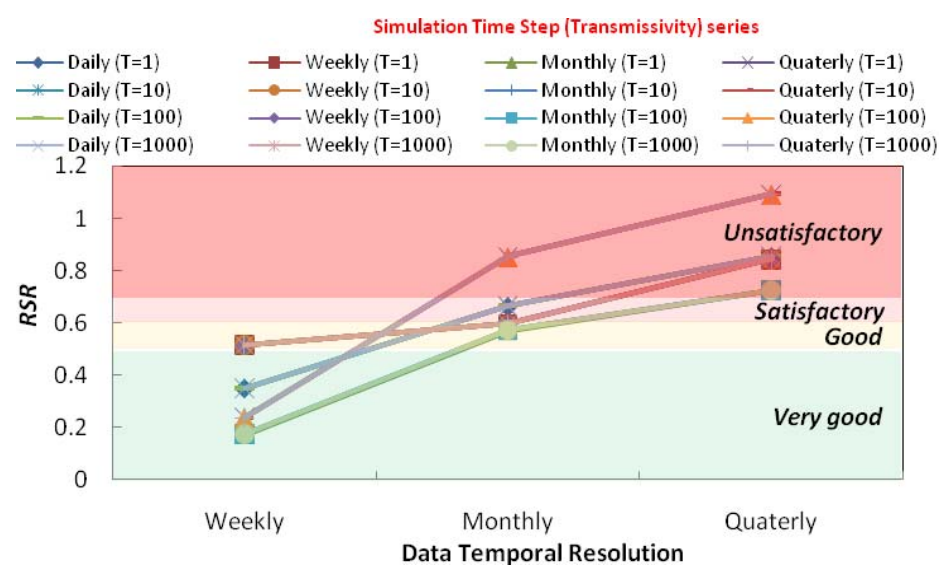

Fig. 7 - Variation of the $R S R$ values for the different scenarios considered to illustrate the effect of the data temporal resolution from a specified head $\mathrm{BC}$ 


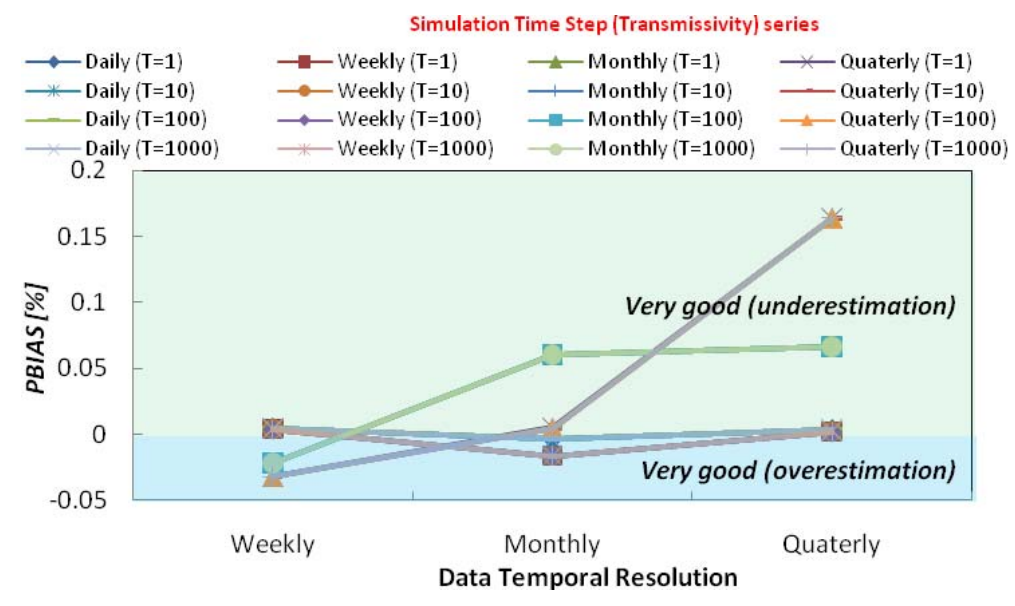

Fig. 8 - Variation of the $P B I A S$ values for the different scenarios considered to illustrate the effect of the data resolution from a specified head

\subsubsection{Simulation Time Step Variation Effect}

In order to assess the effect of the simulation time step (STS) on the considered parameter (specified head), we calculate NSE, PBIAS and RSR. These calculations are conducted by comparing the calculated hydraulic head in the domain midpoint using weekly, monthly and quarterly STS to that calculated using a daily STS (that will be considered as the observed value when using equations (2-4)).

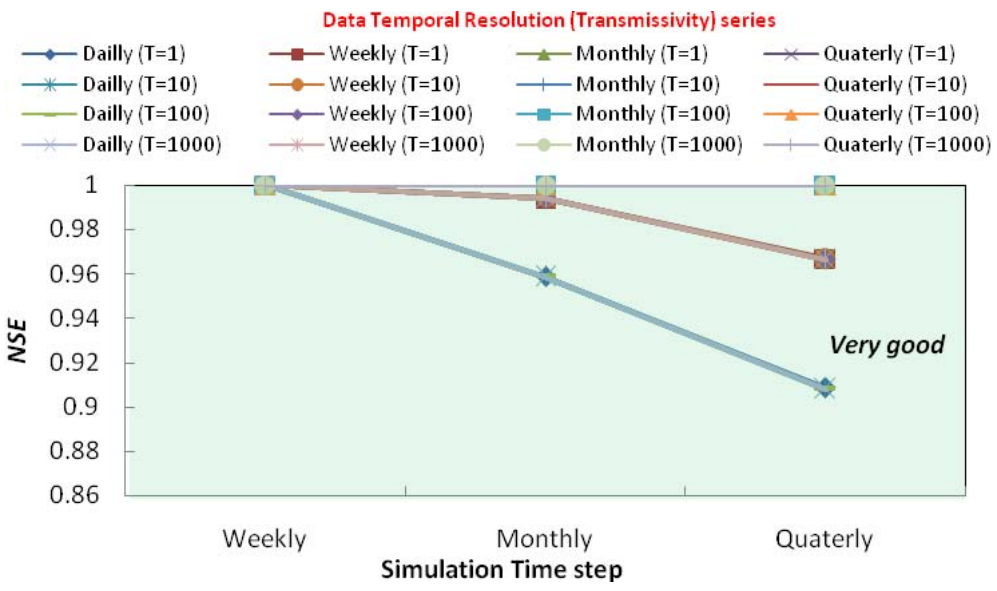

Fig. 9 - Variation of $N S E$ values for the different scenarios considered to illustrate the effect of the simulation time step from a specified head BC

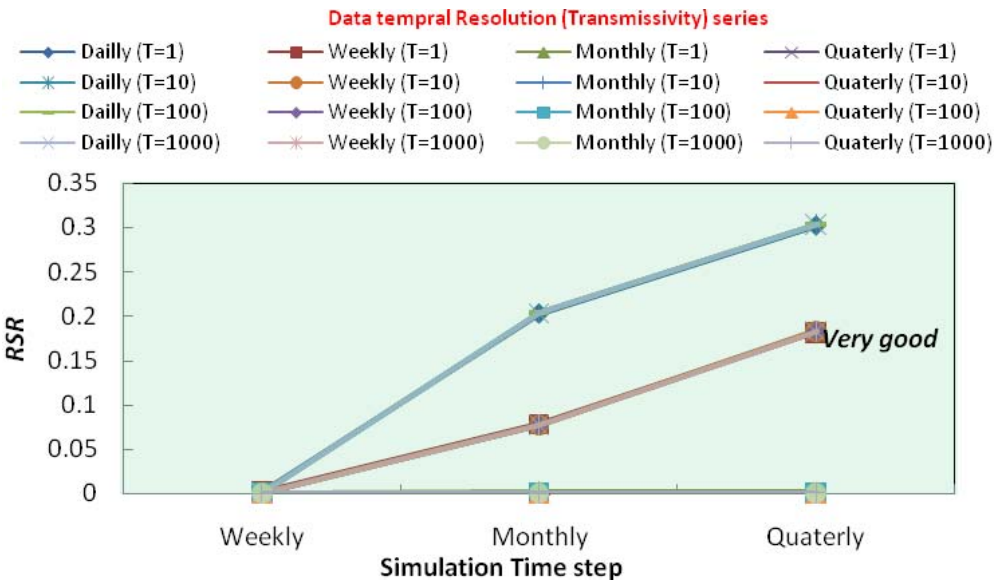

Fig. 10 - Variation of $R S R$ values for the different scenarios considered to illustrate the effect of the simulation time step from a specified head BC 


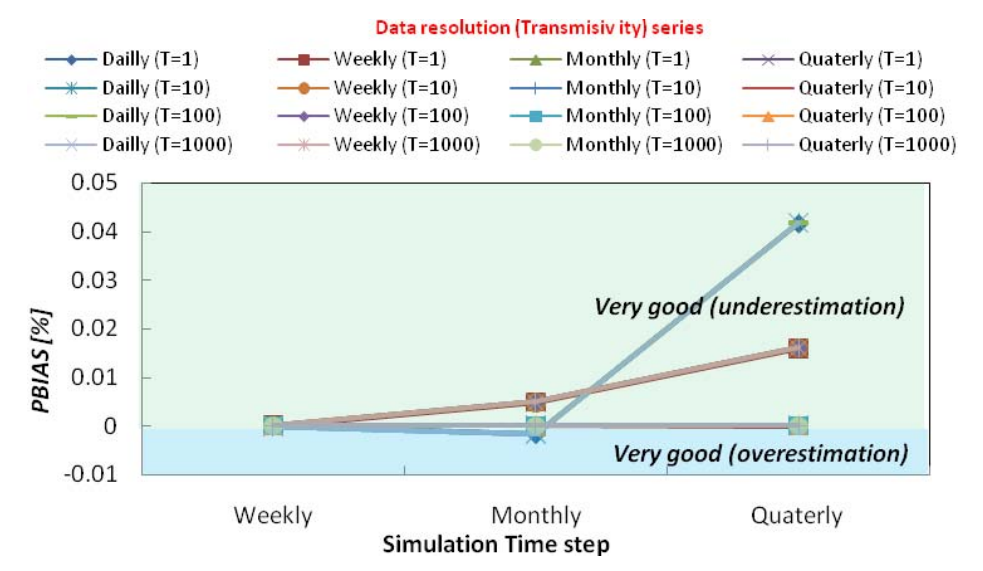

Fig. 11 - Variation of the $P B I A S$ values for the different scenarios considered to illustrate the effect of the simulation time step from a specified head BC

The obtained values of NSE, RSR and PBIAS for the assessment of the effect of the STS experiment are presented in Figures 9-11. The calculated values of these three statistical parameters indicate that the resulting performances are very good. The increase of the time step for a given model configuration is accompanied with a negligible overestimation (since all the obtained values of the PBIAS are negative as shown in Figure 11). Also a decrease in the model performance is observed when STS increases.

This study shows clearly that the effect of the variation of STS is small compared to that induced by the variation of DTR. However, even if this effect is small or negligible if considered separately, it may lead to a poor performance when it is superposed to the effects of other parameters.

It must also be noted that the data comparison is done with discrete variables (hydraulic head values at time characterized as being a multiple of the STS). And so, even if the statistical parameters might indicate an acceptable level of performance, this performance is at the level of the characteristic times (multiples of STS). Consequently, the real comportment of the modeled system can be completely deferent between two consecutive time steps than the comportment obtained from the interpolation of the values calculated at each time step.

The time effect due to the dynamic comportment of a specified head boundary condition in groundwater modeling can be classified into: data temporal resolution and simulation time step (or numerical model integration time step). It is obvious that a model precision and performance increase when the DTR increases and when the STS decreases and unfortunately so does the modeling cost (computing time, data volume, etc.). This creates the necessity of finding a compromise between performance and cost.

The modeling time step should take into consideration:

- The data temporal resolution; and

- The minimal time necessary to obtain a system response at the minimal spatial distance (spatial scale).

One can pre-estimate the necessary time for a hydrological system to respond for a dynamic variation of a specified head using Darcy's law:

$$
v=K \frac{d x}{d t} \cong K \frac{\Delta x}{\Delta t}
$$

Where, $v$ is the flow velocity, $K$ is the saturated hydraulic conductivity, $\Delta h$ is the variation of the hydraulic head between two points and $\Delta x$ is distance travelled by water between these two points. The flow velocity can be written as (where $t$ is time):

$$
v=\frac{d x}{d t} \cong \frac{\Delta x}{\Delta t}
$$


From equations (5) and (6)Error! Reference source not found., it can be observed that the minimal time $(\Delta t)$ necessary for a hydrogeological system to respond for a dynamic variation in the hydraulic head $(\Delta h)$ between the smallest data resolution is inversely proportional to the product of $K$ and $\Delta h$ (equation (7)).

$$
\Delta t \propto \frac{1}{K \times \Delta h}
$$

\subsection{Specified Recharge Rate}

The obtained variations of the hydraulic head at the midpoint of the studied domain for combinations of the parameter values given in Table 1 are presented in Figure 12. Note that in this figure, the results obtained using daily DTR and STS bigger than daily are not presented, because for these scenarios the numerical model does not converge to a solution.

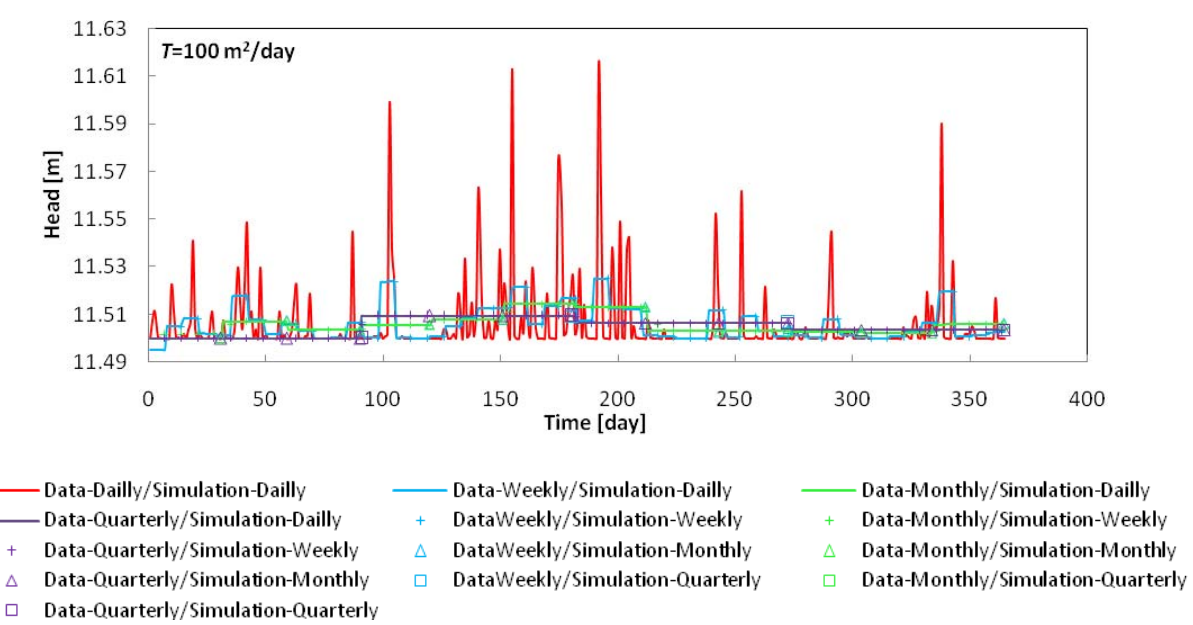

Fig. 12 - Variation of the hydraulic head in the midpoint of the studied domain (time effect from a specified recharge rate experiment)

Those scenarios that do not converge to a solution because the daily data resolution contain recharge values, that if applied to a period longer than one day (over a week, month or a quarter), they will lead to extremely exaggerated increase of the hydraulic head and consequently to incompatible solutions. The applicability of such recharge values during a period longer than a day is due to the method with which Modflow estimates the recharge from a daily DTR when the STS in bigger than daily. This method consists on a linear interpolation of the daily recharges at the extremities of the corresponding STS. Figure 13 describes this method when the recharge is introduced with a daily DTR and when the STS is bigger than daily (weekly for this example). The appropriate variation data when using a weekly STS is represented by the weekly DTR estimated by averaging the daily values.

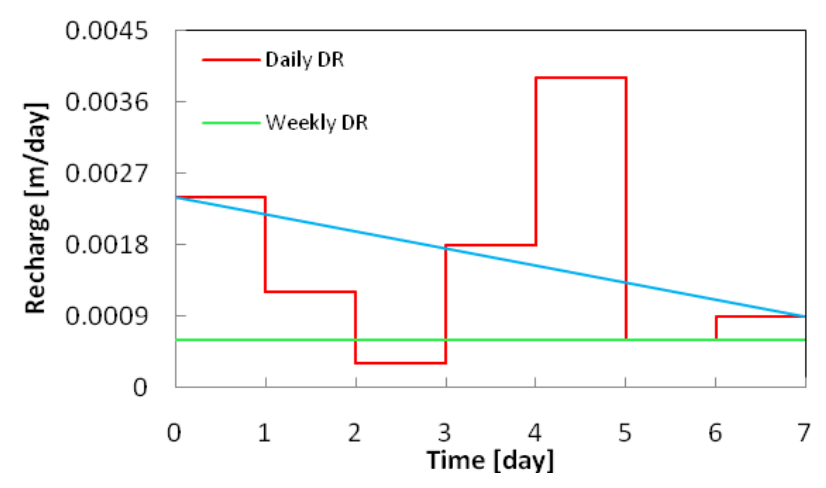


Fig. 13 - Description of the method used by Modflow to estimate the variation of the recharge when STS is bigger than DTR

\subsubsection{Data Resolution Variation Effect}

In order to assess the effect of the data resolution variation on the considered parameter (recharge rate), we calculate NSE, PBIAS and RSR. These calculations are conducted by comparing the calculated hydraulic head in the domain midpoint using:

- Monthly and quarterly data resolution to that calculated using a weekly data resolution (that will be considered as the observed value when using equations (2-4)) for STS higher than daily;

- Weekly, monthly and quarterly data resolution to that calculated using a daily data resolution (that will be considered as the observed value when using equations (2-4)) for daily STS.

Figure 14 shows the obtained values of NSE to assess the effect of DTR from a specified recharge BC. It was found that the use of DTR smaller than STS will lead for unsatisfactory performance and that the model performance decreases when DTR decreases. Similar results were obtained from the SRS parameter (see Figure 15). The PBIAS parameter indicates a general tendency of system response underestimation that increases when DTR decreases (see Figure 16).

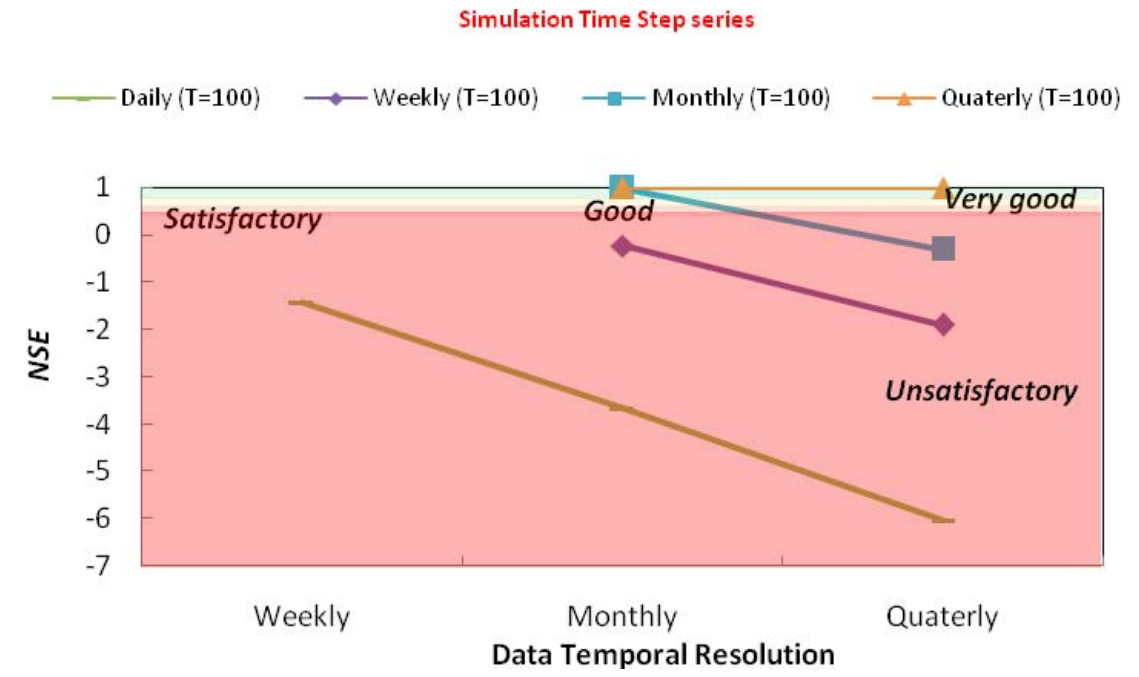

Fig. 14 - Variation of the NSE values for the different scenarios considered to illustrate the effect of the data resolution from a recharge rate

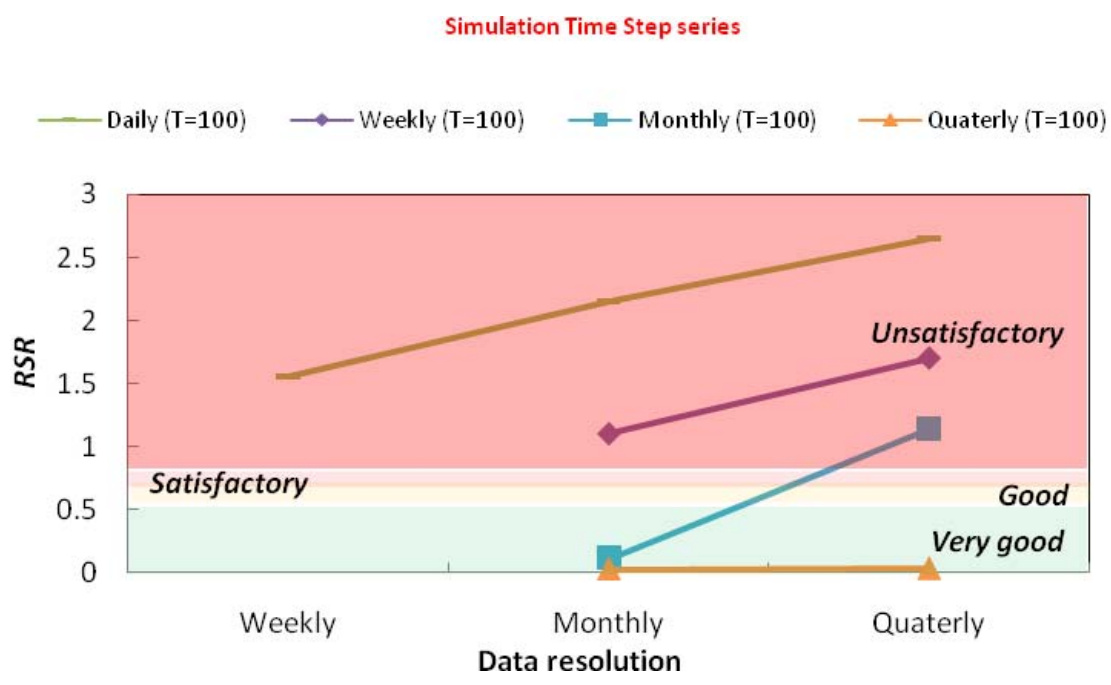


Fig. 15 - Variation of the $R S R$ values for the different scenarios considered to illustrate the effect of the data resolution from a recharge rate

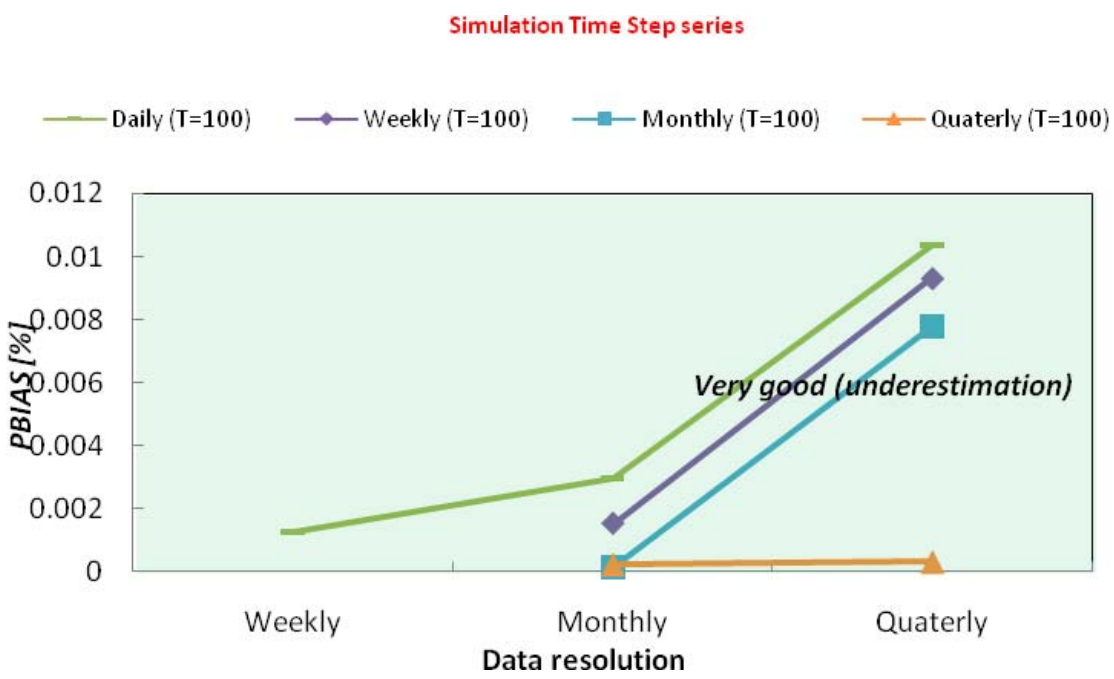

Fig. 16 - Variation of the $P B I A S$ values for the different scenarios considered to illustrate the effect of the data resolution from a recharge rate

Furthermore, the obtained results indicate that the data temporal resolution effect induced by a specified recharge rate $\mathrm{BC}$ on a hydrogeological system response is more significant compared to that induced from a specified head BC.

\subsubsection{Simulation Time Step Variation Effect}

The assessment of the effect of STS on the considered parameter is done similarly as done for the assessment of the effect of STS from the specified head on a hydrogeological system response.

The obtained values of NSE and RSR show that the system performance goes from very good when the STS is smaller or equal to DTR, to unsatisfactory otherwise (as it is clearly represented in Figure 17 and Figure 18). The variation of PBIAS indicates a general tendency of system response underestimation with an effect directly proportional to STS (see Figure 19).

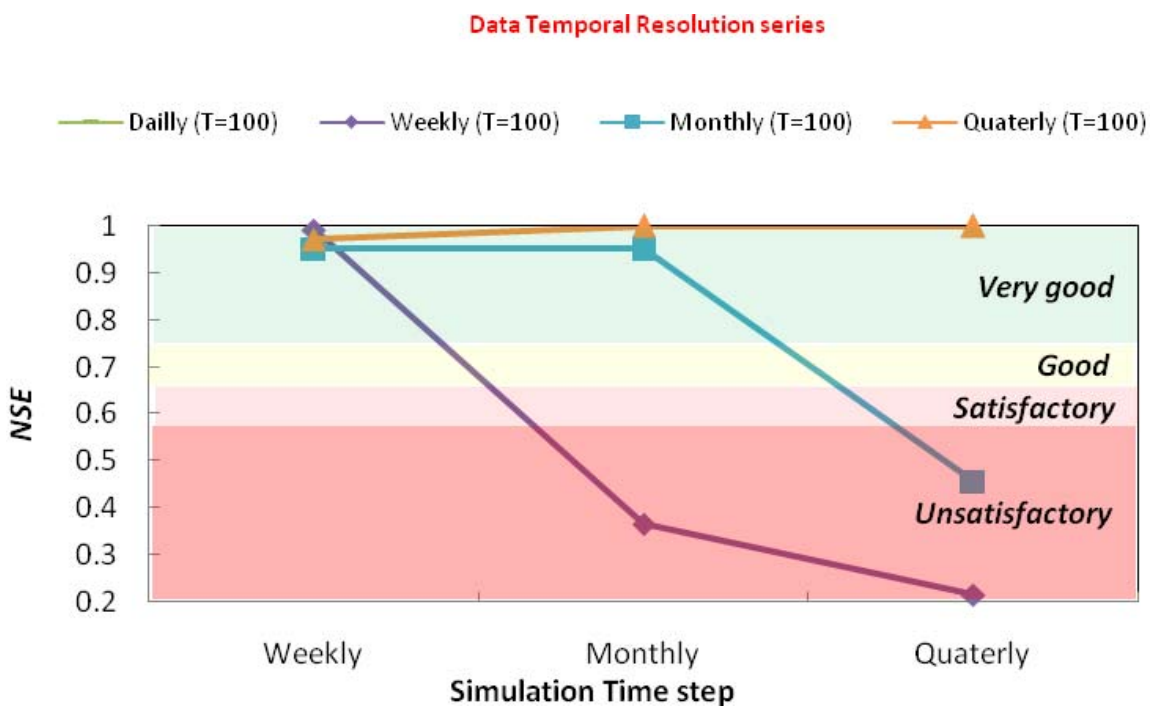

Fig. 17 - Variation of NSE values for the different scenarios considered to illustrate the effect of the simulation time step from a specified recharge rate 

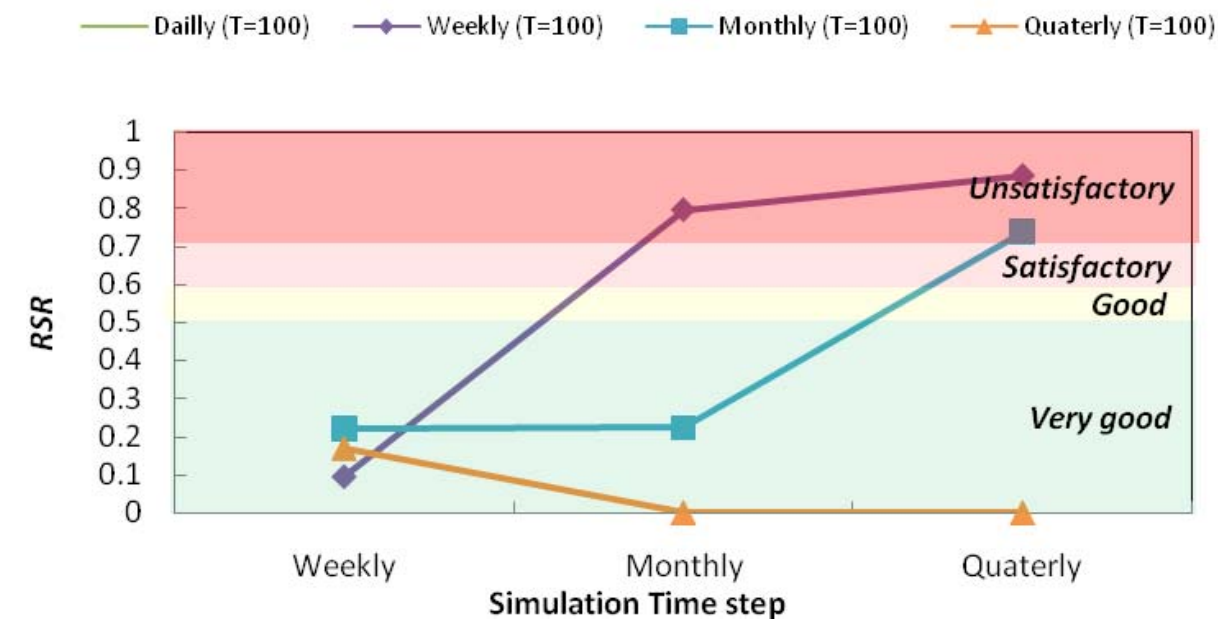

Fig. 18 - Variation of $R S R$ values for the different scenarios considered to illustrate the effect of the simulation time step from a specified recharge rate

The impact of STS is less important compared to that of DTR, but unlike its effect from a specified head (where the change of STS for a given DTR keeps the model performance in the very good zone), it is not negligible when dealing with a recharge rate (where the use of a STS bigger than DTR will result of the jump of the model performance from very good to unsatisfactory).

Data Temporal Resolution series

$\longrightarrow$ Dailly $(T=100) \longrightarrow$ Weekly $(T=100) \quad \longrightarrow$ Monthly $(T=100) \quad$ Quaterly $(T=100)$

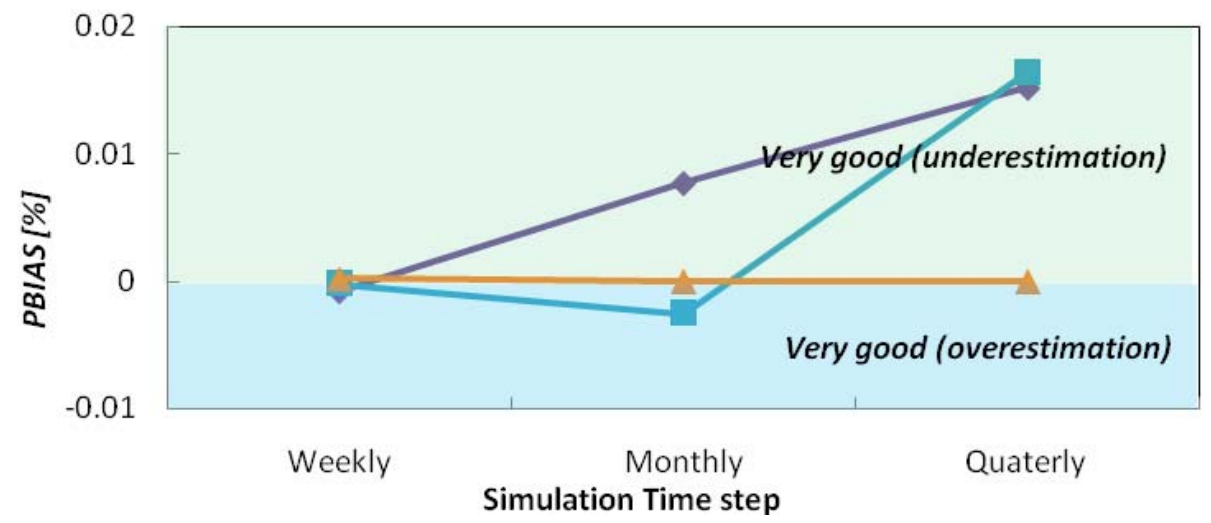

Fig.19 - Variation of PBIAS values for the different scenarios considered to illustrate the effect of the simulation time step from a specified recharge rate

The time effect due to the dynamic comportment of a recharge rate $\mathrm{BC}$ in groundwater flow modeling is more visible than that due to the dynamic character of a specified head. It was observed that the use of a simulation time step bigger than the data temporal resolution will lead to an unsatisfactory model performance.

From this study, it is recommended that for the recharge rate, the smallest DTR (daily) as well as the smallest STS (daily for our case) should be used. 


\section{Conclusion}

The time effect due to the dynamic comportment of a specified head or a specified recharge rate boundary condition types in groundwater flow modeling can be classified into:

- Data temporal resolution;

- Simulation time step.

The conducted parametric studies on the temporal domain discretizing effect showed that:

- Effect induced by the dynamic nature of a recharge rate $\mathrm{BC}$ type is more important on hydrogeological models response than that induced by the dynamic nature of a specified head BC type. Consequently, the temporal discretization of hydrogeological domains would be controlled by the first $\mathrm{BC}$ type;

- The choice of the numerical model integration time step depends on the data temporal resolution;

- For a recharge rate $\mathrm{BC}$ type, data temporal resolution smaller than the simulation time step are to be avoided. A special preprocessing of these data must be done in order to transform the data resolution into a new one at least equal to the simulation time step. The preprocessed data at a lower data temporal resolution must insure a system response equivalent to that obtained using the raw data resolution;

- Since recharge rate $\mathrm{BC}$ type principally represents the groundwater recharge from precipitation, which in turn is controlled by hydrological processes (precipitation and evapotranspiration), a better description will be obtained using hydrologically recommended time steps ( 1 hour); as for the conducted study, the use of the smallest time step possible (daily time step) or smaller was recommended.

- From the study of the dynamic effect of specified head BC type on the response of hydrogeological systems, it was found that the simulation time step should be smaller than the inverse of the product of $K$ and the maximal value of $\Delta h$, obtained from two successive data (specified head) values separated by one data temporal resolution.

\section{Acknowledgements}

This work is supported by the National Authority for Scientific Research of Romania, in the framework of the project "Sedimentary media modeling platform for groundwater management in urban areas (SIMPA)", no.660.

\section{References}

[1] Ostrowski, M., Bach, M., Gamerith, V. \& De Simone, S. (2010). Analysis of the time-step dependency of parameters in conceptual hydrological models. Institut Wasserbau und Wasserwirtschaft, Technische Universität Darmstadt, Germany

[2] Mitchell, G. \& Diaper, C. (2006). Simulating the urban water and contaminant cycle. Environmental Modelling \& Software. 21, 129-134. DOI:10.1016/j.envsoft.2005.03.003.

[3] Mohrlok, U., Wolf, L. \& Klinger, J. (2007). Quantification of infiltration processes in urban areas by accounting for spatial parameter variability. Journal of Soils and Sediments. 8(1), 34-42. DOI: $10.1065 /$ jss2007.05.225.

[4] Downer, C.W. \& Ogden, F.L. (2004). Appropriate vertical discretization of Richards' equation for twodimensional watershed-scale modeling. Hydrological Processes. 18, 1-22. DOI: 10.1002/hyp.1306.

[5] Tustsumi, A., Jinno, K. \& Berndtsson, R. (2004). Surface and subsurface water balance estimation by the groundwater recharge model and a 3-D two-phase flow model. Hydrological Sciences Journal. 49(2), 205-226. DOI: $10.1623 /$ hysj.49.2.205.34837. 
[6] Sutanudjaja, E.H., van Beek, L.P.H, Jong, S.M., van Geer, F.C. \& Bierkens, M.F.P (2011) Large-scale groundwater modeling using global datasets: a test case for the Rhine-Meuse basin. Hydrol. Earth Syst. Sci. Discuss. 8, 2555-2608. DOI: 10.5194/hessd-8-2555-2011.

[7] Berendrecht, W.L., Lourens, A., Snepvangers, J.J.J.C. \& Minnema, B. (2007). Large-Scale High-Resolution Groundwater Modelling using Grid Computing. Oxley, L. \& Kulasiri, D. Eds. MODSIM. International Congress on Modelling and Simulation. Modelling and Simulation Society of Australia and New Zealand.

[8] Kostiakov, A.N. (1932). On the Dynamics of the Coefficient of Water Percolation in Soils and on the Necessity of Studying it from a Dynamic Point of View for the Purposes of Amelioration. Trans. Com. Int. Soc. Soil Sci. 6th. Moscow.

[9] Maniak, U. (1997). Hydrologie Und Wasserwirtschaft: Eine Einfuhrung Fur Ingenieure. 4th ed. Springer.

[10] Harbaugh, A.W., Banta, E.R., Hill, M.C. \& McDonald, M.G. (2000). User guide to modularization concepts and the ground-water flow process. MODFLOW-2000. The U.S. Geological Survey modular ground-water model. Open File Rep. USGS.

[11] Nash, J.E. \& Sutcliffe, J.V. (1970). River flow forecasting through conceptual models: Part 1. A discussion of principles. Journal of Hydrology. 10(3), 282-290. DOI: 10.1016/0022-1694(70)90255-6

[12] Gupta, H.V., Sorooshian, S. \& Yapo, P.O. (1999). Status of automatic calibration for hydrologic models: Comparison with multilevel expert calibration. J. Hydrologic Eng. 4(2), 135-143. DOI: 10.1061/(ASCE)10840699(1999)4:2(135)

[13] Singh, J., Knapp, H.V. \& Demissie, M. (2004). Hydrologic modeling of the Iroquois River watershed using HSPF and SWAT. ISWS CR 2004-08. Champaign, Ill.: Illinois State Water Survey.

[14] Moriasi, D.N., Arnold, J.G, van Liew, M.W., Bingner, R.L., Harmel, R.D \& Veith, T.L. (2007). Model evaluation guidelines for systematic quantification of accuracy in watershed simulations. American Society of Agricultural and Biological Engineers. 50(3), 885-900. 